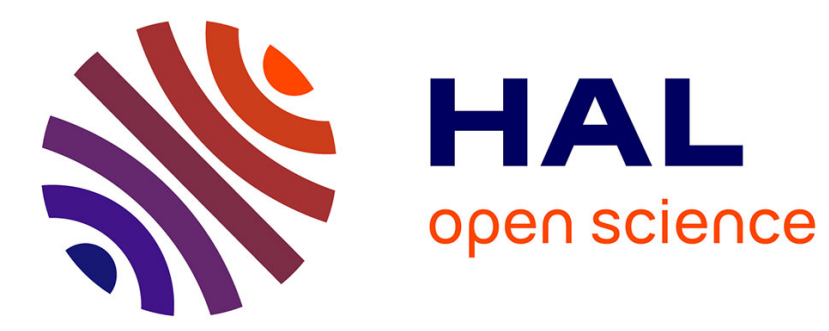

\title{
Retrieving the effective radius of Saharan dust coarse mode from AIRS
}

Clémence Pierangelo, Michael Mishchenko, Yves Balkanski, Alain Chédin

\section{To cite this version:}

Clémence Pierangelo, Michael Mishchenko, Yves Balkanski, Alain Chédin. Retrieving the effective radius of Saharan dust coarse mode from AIRS. Geophysical Research Letters, 2005, 32 (20), pp.L20813. 10.1029/2005GL023425 . hal-02873995

\section{HAL Id: hal-02873995 \\ https://hal.science/hal-02873995}

Submitted on 18 Jun 2020

HAL is a multi-disciplinary open access archive for the deposit and dissemination of scientific research documents, whether they are published or not. The documents may come from teaching and research institutions in France or abroad, or from public or private research centers.
L'archive ouverte pluridisciplinaire HAL, est destinée au dépôt et à la diffusion de documents scientifiques de niveau recherche, publiés ou non, émanant des établissements d'enseignement et de recherche français ou étrangers, des laboratoires publics ou privés. 


\title{
Retrieving the effective radius of Saharan dust coarse mode from AIRS
}

\author{
Clémence Pierangelo, ${ }^{1}$ Michael Mishchenko, ${ }^{2}$ Yves Balkanski, ${ }^{3}$ and Alain Chédin ${ }^{1}$ \\ Received 6 May 2005; revised 8 September 2005; accepted 21 September 2005; published 27 October 2005.
}

[1] We show that the effective radius of the dust coarse mode can be retrieved from Aqua/AIRS observations, using a two step process. First, for each AIRS observation, the dust infrared optical depth, the mean altitude of the dust layer and an estimate of the temperature and water vapor profiles are obtained from 8 spectral channels, using a Look-Up-Table approach. Second, the effective radius is obtained from an additional AIRS channel (located at $9.32 \mu \mathrm{m})$, selected for its sensitivity to dust particle size and its insensitivity to dust particle shape or to other potential contaminants (ozone, for example). The dust coarse mode effective radius is retrieved from AIRS over the Atlantic Ocean for the period April to June 2003. It compares well with in situ measurements, transport model simulations and sun-photometer retrievals. We find that the coarse mode effective radius decreases slightly with transport distance, from $2.4 \mu \mathrm{m}$ to about $2 \mu \mathrm{m}$. Citation: Pierangelo, C., M. Mishchenko, Y. Balkanski, and A. Chédin (2005), Retrieving the effective radius of Saharan dust coarse mode from AIRS, Geophys. Res. Lett., 32, L20813, doi:10.1029/ 2005 GL023425.

\section{Introduction}

[2] The last report of the Intergovernmental Panel on Climate Change (IPCC) [2001] has emphasized low level of understanding of aerosol radiative forcing. Aerosol radiative forcing is caused by both anthropogenic aerosols, such as sulfates, and natural aerosols, such as mineral dust. Indeed, dust originates from natural sources, especially large deserts such as the Sahara, but the question of how much of the dust load comes from anthropogenically disturbed soils is still open [Tegen et al., 2004; Mahowald et al., 2004].

[3] Dust particle size is a key parameter in assessments of the clear-sky shortwave aerosol forcing [Liao and Seinfeld, 1998], which explains why a large number of in situ or spatial remote sensing experiments have been performed to retrieve information on dust size distribution. For instance, bimodal size distributions can be retrieved from the Aerosol Robotic Network (AERONET) ground-based sun-photometers observations [Dubovik and King, 2000]. Because of the significant spatial and temporal variability of dust events, a satellite approach is necessary to obtain global size measurements for use in climatological models. On board

\footnotetext{
${ }^{1}$ Laboratoire de Météorologie Dynamique, Institut Pierre-Simon Laplace, Ecole Polytechnique, Palaiseau, France.

${ }^{2}$ NASA Goddard Institute for Space Studies, Columbia University, New York, USA.

${ }^{3}$ Laboratoire des Sciences du Climat et de L'Environnement, Institut Pierre-Simon Laplace/Commissariat àl'Energie Atomique, Gif-sur Yvette, France.
}

Copyright 2005 by the American Geophysical Union. 0094-8276/05/2005GL023425 the Terra and Aqua platforms, the Moderate resolution Imaging Spectroradiometer (MODIS) is able to retrieve the aerosol effective radius over the oceans [Tanré et al., 1996]. However, Levy et al. [2003] have shown that some disagreements between the MODIS retrievals and in situ measurements still occur. Moreover, even in situ techniques exhibit a wide range of variation in the estimated effective radius, especially for dust, since measurements of coarse particles remain difficult [Reid et al., 2003]. Consequently, dust size, together with dust mineralogical composition, remains a major source of uncertainty in radiative forcing calculations.

[4] In this paper, we introduce a new method to retrieve a variable of particular interest in dust size characterization, namely the coarse mode effective radius, from the observations made by the Atmospheric Infrared Sounder (AIRS). Because this technique uses measurements in the thermal infrared (roughly from $4 \mu \mathrm{m}$ to $12 \mu \mathrm{m}$ ), it provides a new way to characterize dust size distribution, independently of previously developed solar remote sensing algorithms.

\section{Data and Method}

[5] The Atmospheric Infrared Sounder (AIRS), on board the polar NASA platform Aqua, was launched in May 2002. AIRS provides very high spectral resolution measurements of radiation emitted by the Earth surface and atmosphere in the spectral range $3.7 \mu \mathrm{m}$ to $15.4 \mu \mathrm{m}$. Each of its 2378 channels has a spectral resolution given by $\lambda / \Delta \lambda=1200$. A 324 channel subset of the AIRS data is currently distributed by NOAA/NESDIS [Goldberg et al., 2003], and archived at Laboratoire de Météorologie Dynamique since April 2003. In the following, infrared, or thermal infrared, will refer to the wavelength range $3.75 \mu \mathrm{m}\left(2670 \mathrm{~cm}^{-1}\right)$ to $15.4 \mu \mathrm{m}$ $\left(650 \mathrm{~cm}^{-1}\right)$. The $10 \mu \mathrm{m}$ wavelength, which roughly corresponds to the maximum of the infrared emission from the Earth, is chosen herein as the reference wavelength for infrared optical depth.

[6] The refractive indices of dust are taken from the "mineral transported" model of the "Optical Properties of Aerosols and Clouds" data set [Hess et al., 1998].

\subsection{Sensitivity Study}

[7] The influence of dust particle size distribution (PSD) on infrared optical properties (absorption and scattering) is evaluated with a Mie code, and the effect of dust PSD on AIRS radiances is then simulated with a radiative transfer code.

[8] There are many observations proving that dust PSD is bimodal [e.g., Dubovik et al., 2002]. However, to compute dust extinction at the reference $10 \mu \mathrm{m}$ wavelength, we can consider the PSD as a monomodal lognormal distribution, since simulations with a Mie code (not shown) demonstrate that the contribution of the 


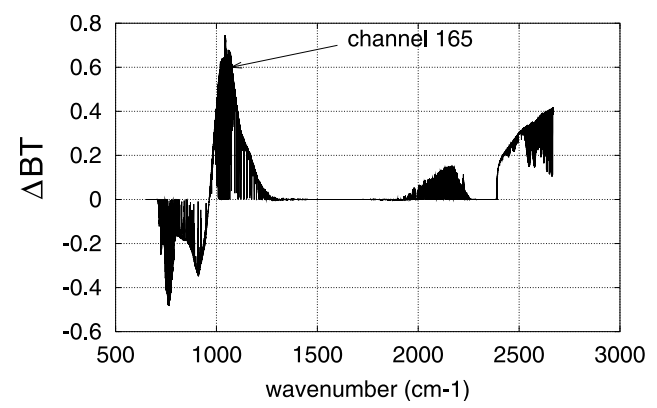

Figure 1. Sensitivity to particle size distribution at infrared wavelengths. $\triangle \mathrm{BT}$ : Difference $(\mathrm{K})$ between the brightness temperature calculated for a dust layer made of particles with an effective radius of $3 \mu \mathrm{m}$ and the brightness temperature calculated for a dust layer made of particles with an effective radius of $1 \mu \mathrm{m}$.

accumulation mode to the total optical depth is below $10 \%$. Indeed, infrared radiation mostly interacts with coarse mode particles. Besides, Mie calculations also show that the width of the distribution has a negligible impact on aerosol optical properties in the thermal infrared. This allows reducing the number of parameters of the PSD to only one: the coarse mode effective radius, which is the most significant size parameter in term of radiative impact. For instance, the impact of the geometric standard deviation of the PSD (in the range 1.6 to 2.5) on the normalized extinction coefficient between 3.8 and $15 \mu \mathrm{m}$ is below $10 \%$. The geometric standard deviation of the distribution has been fixed at 2.2, in agreement with in situ measurements reported by Reid et al. [2003].

[9] With these assumptions, infrared spectrum simulations were performed with a radiative transfer model coupling the line-by-line "Automatized Atmospheric Absorption Atlas" [Scott and Chédin, 1981] (also see http://ara.lmd.polytechnique.fr) and the Discrete Ordinate algorithm [Stamnes et al., 1988], at a spectral resolution of $0.02 \mathrm{~cm}^{-1}$. For convenience, the radiances simulated by the radiative transfer code are converted into their equivalent brightness temperatures (BTs). For a tropical situation, with an homogeneous dust layer located between $2000 \mathrm{~m}$ and $2700 \mathrm{~m}$, and an aerosol optical depth of 0.6 at $10 \mu \mathrm{m}$, Figure 1 shows the difference between BTs calculated with a dust layer composed of a PSD with an effective radius of $3 \mu \mathrm{m}$ and a PSD with an effective radius of $1 \mu \mathrm{m}$. We see that the impact of a change in the effective radius on BTs strongly depends on the wavelength considered. The effect of particle size at infrared wavelengths is of the order of a few tenths of $\mathrm{K}$, which is about 10 times smaller than the decrease in BTs caused by the presence of dust.

\subsection{Retrieval Algorithm}

[10] The effective radius retrieval is a two step process. First, for each AIRS observation (clear sky), the dust extinction optical depth at $10 \mu \mathrm{m}$, the mean altitude of the dust layer and an estimate of the temperature and water vapor profiles (a so-called "atmospheric situation") are obtained from 8 channel measurements, using a Look-UpTable (LUT) approach as described by Pierangelo et al.
[2004]. Second, once these parameters have been determined, an additional AIRS channel, located at $1072.5 \mathrm{~cm}^{-1}$ or $9.32 \mu \mathrm{m}$ (channel number 165 in the 1-324 range numbering, see arrow in Figure 1), yields the effective radius. This channel has been selected according to the following criteria: maximum sensitivity to dust size, no sensitivity to atmospheric variable components (such as ozone or sulfates), and no sensitivity to dust asphericity. As an example, Figure 2 shows a simulation of channel $165 \mathrm{BT}$ as a function of dust coarse mode effective radius (ranging from 0.5 to $5 \mu \mathrm{m}$ ), for one given tropical atmospheric situation, for an aerosol optical depth (AOD) of 0.6 (at $10 \mu \mathrm{m}$ ), and a mean altitude of the dust layer of $3500 \mathrm{~m}$. Such pre-computed simulations are done for every dust infrared optical depth (21 values from 0.01 to 2.0$)$, for every dust layer altitude ( 9 values from $500 \mathrm{~m}$ to $6500 \mathrm{~m}$ ), and for almost 600 atmospheric situations of the LUT. Using the atmospheric and aerosol parameters retrieved from the first step, we compare the observed value of the 165-channel BT to the plot of Figure 2, which provides the effective radius by linear interpolation.

[11] Because the sensitivity of channel-165 BT decreases with decreasing dust optical depth or altitude, only AIRS observations where AOD is greater than 0.2 and the mean altitude of the dust layer is greater than $1300 \mathrm{~m}$ are considered. As high resolution infrared emissivities may vary substantially with frequency over land surfaces, the retrieval is presently limited to areas over the oceans. Moreover, only night-time observations are considered, in order to avoid solar contamination of near-infrared channels used in the first step of the retrieval.

\subsection{Performance of the Algorithm}

[12] The ability of this algorithm to retrieve dust effective radius has been evaluated with simulations. For each value of the effective radius, from $0.5 \mu \mathrm{m}$ to $5 \mu \mathrm{m}$, about 60000 simulated situations have been tested by varying the dust AOD, altitude and atmospheric situation. The effective radius is retrieved with an accuracy varying from $0.5 \mu \mathrm{m}$ for smaller radii to $1 \mu \mathrm{m}$ for larger radii (Figure 3). There is a slight underestimation (resp. overestimation) of large

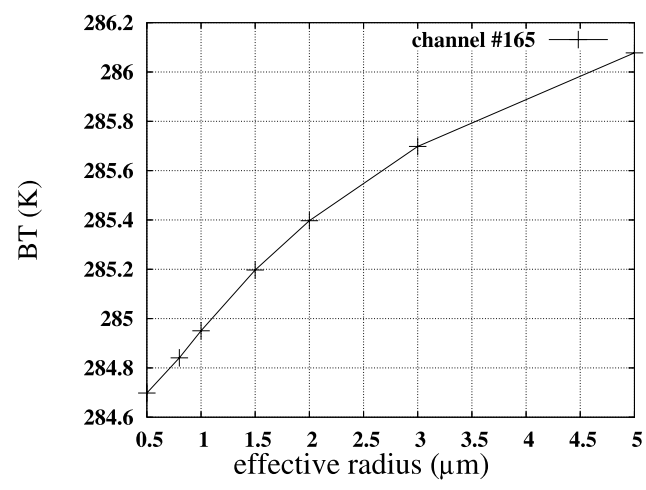

Figure 2. AIRS channel $165\left(1072.5 \mathrm{~cm}^{-1}\right)$ sensitivity to particle size distribution: brightness temperature as a function of dust effective radius for a tropical situation with a dust layer located at $3500 \mathrm{~m}$ and an optical depth of 0.6 at $10 \mu \mathrm{m}$. 


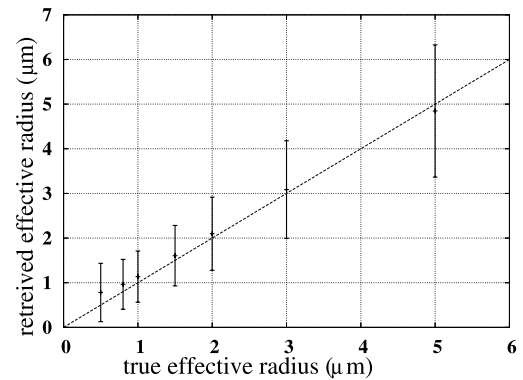

Figure 3. Results of the retrieval algorithm applied to simulations: effective radius retrieved for 7 values of the effective radius used as an input in the simulations. The error bars show the standard deviations of the retrieved values.

(resp. small) values, but no bias in the range $1-3 \mu \mathrm{m}$, where most dust radii are expected to lie.

\section{Results and Discussion}

[13] Saharan dust effective radius (coarse mode only) has been retrieved for the three months of April, May and June 2003 over the Atlantic Ocean, at a spatial resolution of $3.75^{\circ}$ in longitude by $2.5^{\circ}$ in latitude, which is the spatial resolution of the LMDz-INCA model (Laboratoire de Météorologie Dynamique general circulation model - Interaction with Chemistry and Aerosols) [Hauglustaine et al., 2004]. Because of the specific conditions required for generating one retrieval (no water cloud, presence of dust, AOD greater than 0.2), one monthly box may actually contain retrievals for only a few days of observations, especially westward of $45^{\circ} \mathrm{W}$, because the AOD decreases from East to West. This is why the results presented have been averaged over the whole time period (April to June 2003), using a 3 by 3 box running mean (moving one box by one box). There may be a natural day-by-day variation caused by differences between dust event characteristics (e.g., sources), which is reduced by the spatial running mean. Finally, the total number of individual retrievals by box is plotted in Figure 4 (top).

[14] The effective radius of the coarse mode retrieved from AIRS is presented in Figure 4 (middle). The retrieved values are in agreement with literature. For example, Reid et al. [2003] reported in situ measurements of dust mass median diameter from several field campaigns in the range 3 to $9 \mu \mathrm{m}$, corresponding to effective radius in the range 1.2 to $3.6 \mu \mathrm{m}$. The AERONET sun-photometer at Capo Verde also provides the effective radius of the coarse mode (available at http://aeronet.gsfc.nasa.gov/.) Table 1 shows the corresponding monthly means for April to June 2003, for two mineral aerosol models, one spherical and one nonspherical. AIRS values are slightly larger but of the same order. However, AERONET "monthly" means, like AIRS monthly means, are calculated only over a few days, when dust amount is large enough and no cloud is present. Owing to the AERONET retrievals being day-time and the AIRS retrievals being night-time, the scenes observed by AERONET and AIRS are obviously not the same, and the days may also differ, which, at least partly, explains the above difference. Indeed, if we consider a climatology from

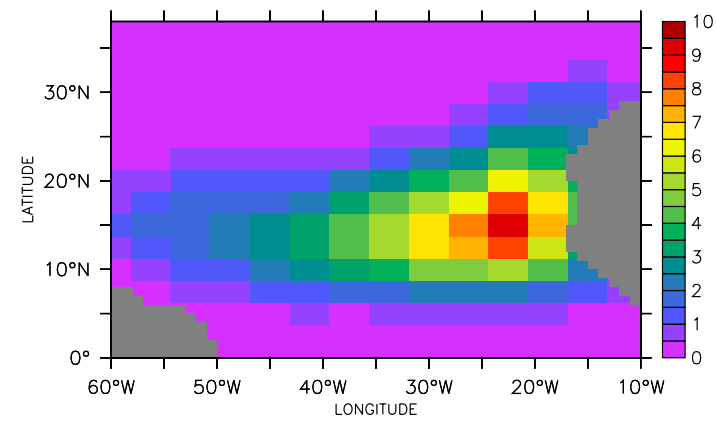

Number of retrievals (AIRS) $(\times 1000)$
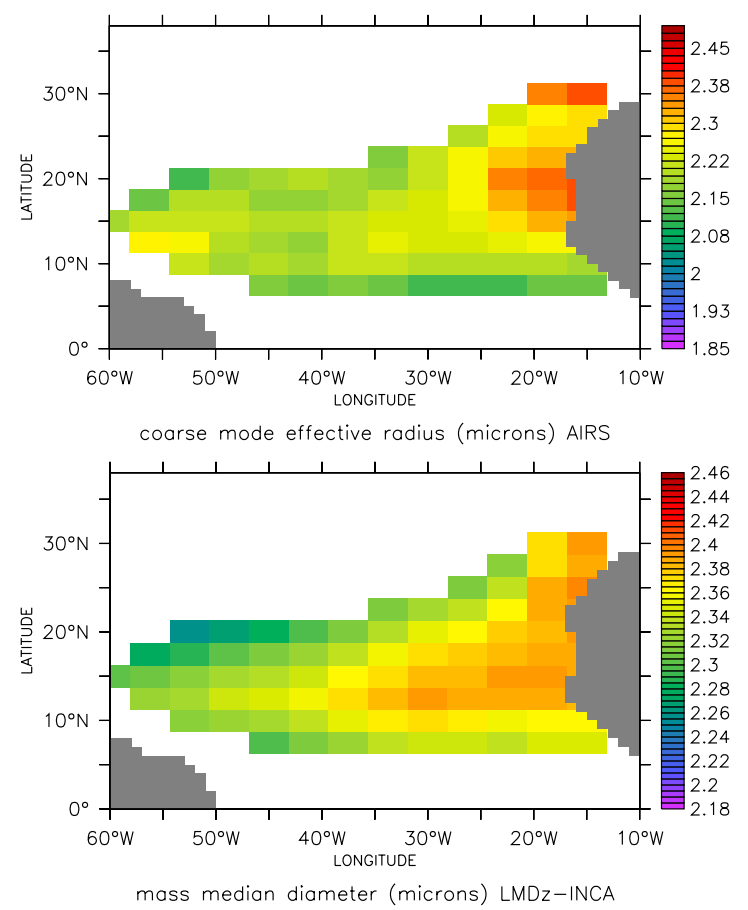

Figure 4. (top) Total number of individual retrievals from AIRS after the spatial running mean. (middle) Mean dust effective radius of the coarse mode for April-June 2003 $(\mu \mathrm{m})$, retrieved from AIRS data. (bottom) Dust mass median diameter for April-June $2003(\mu \mathrm{m})$, simulated with LMDzINCA.

the same AERONET site, the effective radius of the coarse mode is $2.15 \pm 0.10 \mu \mathrm{m}$ [Tanré et al., 2001], in very good agreement with AIRS retrievals.

[15] The reduction in dust size seen in Figure 4 (middle), from $2.4 \mu \mathrm{m}$ near the African coast to $2 \mu \mathrm{m}$ over the west tropical Atlantic, is caused by the distance of transport. It is in agreement with current knowledge and is explained by preferential settling of coarser particles [Maring et al.,

Table 1. Comparison Between Saharan Dust Coarse Mode Effective Radius at Capo Verde Retrieved From AIRS and From AERONET, for April, May, and June 2003

\begin{tabular}{lccr}
\hline & \multicolumn{2}{c}{ Coarse Mode Effective Radius, $\mu \mathrm{m}$} \\
\cline { 2 - 4 } & April & May & June \\
\hline AIRS & 2.02 & 2.27 & 2.14 \\
AERONET & & & \\
$\quad$ Spherical particles & 1.67 & 1.78 & 1.67 \\
$\quad$ Non spherical particles & 1.89 & 1.71 & 1.67 \\
\hline
\end{tabular}


2003]. As an example, we show in Figure 4 (bottom) the dust mass median diameter from the LMDz-INCA model for the same period. Only days when the integrated dust load is above a threshold $\left(0.27 \mathrm{~g} . \mathrm{m}^{-2}\right.$, equivalent to a $10-\mu \mathrm{m}$ AOD of 0.2 ) are kept in the time average, in order to be consistent with the satellite approach. It is impossible to compare quantitatively the two maps since dust is modelled in LMDz-INCA as a monomodal size distribution rather than the sum of an accumulation and a coarse mode. This is a limitation of the monomodal representation of dust PSD in LMDz-INCA. However, there is a rather good agreement in the size pattern, with larger values close to the African coast and an East-West gradient of dust particle sizes. If the AOD is biased by 0.1 , the effective radius is slightly biased too (by $0.11 \mu \mathrm{m}$ ) but these conclusions still hold. Note also that both the AIRS retrievals and the LMDzINCA simulations show larger sizes at the latitude of $30^{\circ} \mathrm{N}$. The AIRS effective radius decreases more abruptly than the LMDz-INCA mass median diameter, as the mass median diameter also takes into account particles in the accumulation mode, less affected by settling during transport than coarse particles.

\section{Conclusions}

[16] A new method to constrain dust size distribution over oceans using high spectral resolution infrared AIRS observations has been developed. It is the first time, to our knowledge, that aerosol effective radius is retrieved from infrared radiances. At visible wavelengths, both the accumulation mode and the coarse mode contribute to the optical depth. Using visible radiances to constrain dust size requires the retrieval of at least three variables (the effective radius of each mode and the concentration ratio between the two modes), which is not yet possible. In contrast, the main advantage of using infrared radiances is the fact that infrared radiation is only sensitive to coarse mode particles, the effect of the accumulation mode and of the width of the distribution being negligible. Therefore, the parameter retrieved is the effective radius of the dust coarse mode. This variable is of particular interest in evaluations of the dust radiative forcing.

[17] For the period April to June 2003, the retrieved effective radius of the Saharan dust coarse mode is in good agreement with in situ measurements. The comparison with AERONET products at Capo Verde is good, even though the AIRS-retrieved effective radii are slightly larger. Because of gravitational settling, the retrieved effective radius is reduced with transport distance (from $2.4 \mu \mathrm{m}$ along the African coast to about $2.0 \mu \mathrm{m}$ over the Caribbean islands). This pattern is consistent with the process of aerosol removal as modelled in LMDz-INCA.

[18] The extension of this study to observations from the Infrared Atmospheric Sounding Interferometer (IASI), scheduled to be launched onboard Metop by the end of 2005 , should be very promising. Access to a higher spectral sampling would make possible not only the use of the present method and the retrieval of the dust effective radius, but also the retrieval of additional information on dust microphysics (e.g., shape and mineralogical composition) by analyzing carefully the information content of each channel.
[19] Acknowledgments. We thank D. Tanré and his staff for establishing and maintaining the AERONET site at Capo-Verde. Thanks to A. Mishchenko for correcting our English!

\section{References}

Dubovik, O., and M. D. King (2000), A flexible inversion algorithm for retrieval of aerosol optical properties from Sun and sky radiance measurements, J. Geophys. Res., 105, doi:10.1029/2000JD900282.

Dubovik, O., B. N. Holben, T. F. Eck, A. Smirnov, Y. J. Kaufman, M. D. King, D. Tanré, and I. Slutsker (2002), Variability of absorption and optical properties of key aerosol types observed in worldwide locations, J. Atmos. Sci., 59, 590-608.

Goldberg, M., Y. Qu, L. M. McMillin, W. Wolf, L. Zhou, and M. Divakarla (2003), AIRS near-real-time products and algorithms in support of operational numerical weather prediction, IEEE Trans. Geosci. Remote Sens., 41, 379-389.

Hauglustaine, D., F. Hourdin, L. Jourdain, M.-A. Filiberti, S. Walters, J. F. Lamarque, and E. A. Holland (2004), Interactive chemistry in the Laboratoire de Météorologie Dynamique general simulation model, description and background tropospheric chemistry evaluation, J. Geophys. Res., 109, D04314, doi:10.1029/2003JD003957.

Hess, M., P. Koepke, and I. Schult (1998), Optical properties of aerosols and clouds: The software package OPAC, Bull. Am. Meteorol. Soc., 79, $831-844$

Intergovernmental Panel on Climate Change (IPCC) (2001), Climate Change 2001: The Scientific Basis: Contribution of Working Group I to the Third Assessment Report of the International Panel on Climate Change, edited by J. T. Houghton et al., 873 pp., Cambridge Univ. Press, New York

Levy, R. C., L. A. Remer, D. Tanré, Y. J. Kaufman, C. Ichoku, B. N. Holben, J. M. Livingston, P. B. Russell, and H. Maring (2003), Evaluation of the Moderate Resolution Imaging Spectroradiometer (MODIS) retrievals of dust aerosol over the ocean during PRIDE, J. Geophys. Res., 108(D19), 8594, doi:10.1029/2002JD002460.

Liao, H., and J. H. Seinfeld (1998), Radiative forcing by mineral dust aerosols: Sensitivity to key variables, J. Geophys. Res., 103, 31,63731,645 .

Mahowald, N. M., G. D. R. Rivera, and C. Luo (2004), Comment on "Relative importance of climate and land use in determining present and future global soil dust emission" by I. Tegen et al., Geophys. Res. Lett., 31, L24105, doi:10.1029/2004GL021272.

Maring, H., D. Savoie, M. Izaguirre, L. Custals, and J. S. Reid (2003), Mineral dust aerosol size distribution change during atmospheric transport, J. Geophys. Res., 108(D19), 8592, doi:10.1029/2002JD002536.

Pierangelo, C., A. Chédin, S. Heilliette, N. Jacquinet-Husson, and R. Armante (2004), Dust altitude and infrared optical depth from AIRS, Atmos. Chem. Phys., 4, 1813-1822.

Reid, J. S., et al. (2003), Comparison of size and morphological measurements of coarse mode dust particles from Africa, J. Geophys. Res., 108(D19), 8593, doi:10.1029/2002JD002485

Scott, N., and A. Chédin (1981), A fast line-by-line method for atmospheric absorption computations: The automatized atmospheric absorption atlas, J. Appl. Meteorol., 20, 802-812.

Stamnes, K., S.-C. Tsay, W. Wiscombe, and K. Jayaweera (1988), Numerically stable algorithm for discrete ordinate-method radiative transfer in multiple scattering and emitting layered media, Appl. Opt., 27, 25022509.

Tanré, D., M. Herman, and Y. J. Kaufman (1996), Information on aerosol size distribution contained in solar reflected radiances, J. Geophys. Res., 101, 19,043-19,060

Tanré, D., Y. J. Kaufman, B. N. Holben, B. Chatenet, A. Karnieli, F. Lavenu, L. Blarel, O. Dubovik, L. A. Remer, and A. Smirnov (2001), Climatology of dust aerosol size distribution and optical properties derived from remotely sensed data in the solar spectrum, J. Geophys. Res., 106, 18,205-18,217.

Tegen, I., M. Werner, S. P. Harrison, and K. E. Kohfeld (2004), Relative importance of climate and land use in determining present and future global soil dust emission, Geophys. Res. Lett., 31, L05105, doi:10.1029/2003GL019216.

Y. Balkanski, Laboratoire des Sciences du Climat et de L'Environnement, Institut Pierre-Simon Laplace/Commissariat à l'Energie Atomique, L'Orme des Merisiers, F-91191 Gif-sur Yvette, France.

A. Chédin and C. Pierangelo, Laboratoire de Météorologie Dynamique, Institut Pierre-Simon Laplace, Ecole Polytechnique, F-91128 Palaiseau, France. (clemence.pierangelo@1md.polytechnique.fr)

M. Mishchenko, NASA Goddard Institute for Space Studies, Columbia University, 2880 Broadway, New York, NY 10025, USA. 